\title{
Microstructure design for fast oxygen conduction - ERRATUM
}

Dilpuneet S. Aidhy and William J. Weber

doi: 10.1557/jmr.2015.327, Published by Materials Research Society with Cambridge University Press, 11 November 2015.

\section{Processing of Al-12Si-TNM composites by selective laser melting and evaluation of compressive and wear properties - ERRATUM}

Konda G. Prashanth, Sergio Scudino, Anil K. Chaubey, Lukas Löber, Pei Wang, Hooyar Attar, Frank P. Schimansky, Florian Pyczak, and Jürgen Eckert.

doi: 10.1557/jmr.2015.326, Published by Materials Research Society with Cambridge University Press, 12 November 2015.

In Aidhy, ${ }^{1}$ there should have been a footnote for co-author William Weber as follows:

This author was an editor of this journal during the review and decision stage. For the JMR policy on review and publication of manuscripts authored by editors, please refer to http://www.mrs.org/jmr-editor-manuscripts/.

In Prashanth, ${ }^{2}$ there should have been a footnote for co-author Jürgen Eckert as follows:

This author was an editor of this journal during the review and decision stage. For the $J M R$ policy on review and publication of manuscripts authored by editors, please refer to http://www.mrs.org/jmr-editor-manuscripts/.

The editors regret these attribution errors, and the originals have since been corrected.

\section{REFERENCES}

1. D.A. Aidhy and J.W. Weber. Microstructure design for fast oxygen conduction. J. Mater. Res. 31(1), 2-16 (2016).

2. K.G. Prashanth, S. Scudino, A.K. Chaubey, L. Löber, P. Wang, H. Attar, F.P. Schimansky, F. Pyczak, and J. Eckert. Processing of Al-12Si-TNM composites by selective laser melting and evaluation of compressive and wear properties. J. Mater. Res. 31(1), 55-65 (2016). 